\title{
EL DEUDOR ANTE LA SOLICITUD DE DECLARACIÓN DE CONCURSO (UNA PRIMERA APROXIMACIÓN AL ARTÍCULO 17 DEL PROYECTO DE LEY CONCURSAL)
}

\author{
M PIA CALDERÓN CUADRADO
}

Profesora titular de Derecho Procesal

Universidad de La Rioja

\section{SUMARIO}

I. SOBRE LAS POSIBLES CONDUCTAS DEL DEUDOR Y SU INCIDENCIA EN EL DESARROLLO PROCEDIMENTAL.

II. ALLANAMIENTO, OMISIÓN DE ACTIVIDAD Y PETICIÓN ULTERIOR COMO CAUSAS DE LA DECLARACIÓN INMEDIATA DE CONCURSO.

1. La posibilidad de conformarse.

1.1 Aspectos básicos del allanamiento.

1.1.1 Acto procesal del deudor. Requisitos subjetivos.

1.1.2 Conformidad con la pretensión. Requisitos objetivos.

1.1.3 Finalización anormal del procedimiento mediante resolución de fondo favorable.

1.2 Forma y tiempo de realización.

2. Falta de oposición.

2.1 Alguna precisión sobre el supuesto de hecho normativo.

2.2 Sus consecuencias jurídicas: estimación de la solicitud.

3. Instancia de propio concurso y auto declarándolo.

III. OPOSICIÓN A LA SOLICITUD Y TRAMITACIÓN CONTRADICTORIA.

1. En general.

2. Los motivos para oponerse. Delimitación negativa y positiva.

3. El acto de oposición, su examen por el tribunal y la citación a comparecencia. 


\section{RESUMEN}

Ante el procedimiento de declaración de concurso, el sujeto pasivo tiene, según el artículo 17 PLC, dos alternativas: allanarse u oponerse. Sin embargo, existen más alternativas: recurrir la providencia de admisión a trámite, plantear declinatoria, no contestar, o presentar solicitud del propio concurso. La autora analiza cada una de las posibilidades del deudor, diferenciando las que originan una resolución judicial estimatoria de la pretensión concursal sin anterior procedimiento contradictorio: allanamiento, inactividad y solicitud de la declaración de concurso; y la oposición del deudor que se plantea como la opción ordinaria a seguir por el sujeto pasivo que exige debate contradictorio en todo caso, analizando los motivos para oponerse y su tramitación.

\section{SOBRE LAS POSIBLES CONDUCTAS DEL DEUDOR Y SU INCIDENCIA EN EL DESARROLLO PROCEDIMENTAL.}

El artículo 17 del PLC se rubrica como "allanamiento u oposición del deudor" y se encuentra situado en el capítulo correspondiente al procedimiento de declaración de concurso; procedimiento que, en este caso, se inicia con la petición del acreedor, o de otro legitimado, admitida a trámite (arts. 3, 6 y 12 PLC). De dicha ubicación y título se desprende con facilidad la existencia de dos líneas alternativas de actuación del sujeto pasivo (del que se afirma su insolvencia) del juicio concursal.

La primera opción, allanarse, supone el reconocimiento de la procedencia de la declaración de concurso instada por el solicitante y conlleva, en consecuencia, la estimación de su pretensión. La segunda postura, oponerse, no es sino la formulación de resistencia, siempre de fondo, en el intento de conseguir el rechazo de aquella petición.

Sin embargo, si bien se mira, y lo confirmaría la propia normativa concursal proyectada, las posibilidades del deudor van más allá de las que acaban de mencionarse. Recurrir la providencia de admisión a trámite (art. 12 PLC), plantear declinatoria (art. 11 PLC), no contestar o presentar solicitud de propio concurso -aunque temporalmente esta última opción se sitúa antes del traslado de la ya formulada (art. 17 PLC)- son también conductas admisibles y no siempre incompatibles con las inicialmente señaladas.

a) Evidentemente, la primera en el tiempo es la solicitud del deudor de propio concurso.

No obstante, y resulta evidente también, esta actitud no puede encuadrarse entre las posibles a adoptar ante o frente la petición del acreedor o de cualquier otro legitimado. La razón es sencilla. Tal conducta se regula como previa a la realización de su emplazamiento y, por consiguiente, teóricamente al menos, a tener conocimiento de aquel acto procesal y su admisión a trámite. Por ello es por lo que no habría inconveniente en que, efectuado el traslado, el deudor adoptara una postura combativa desde una perspectiva procesal -declinatoria o, en su caso, apelación (arts. 11 y 12 PLC)- o, incluso, material (art. 17 PLC). 
Es cierto que los efectos que se anudan a aquel proceder son los mismos que para el allanamiento o la no oposición: declaración inmediata de concurso. Sin embargo, el insolvente puede tener interés tanto en la atribución del conocimiento del juicio universal a un órgano jurisdiccional determinado como en su consideración de voluntario para lo cual sería necesario una decisión de inadmisión o de rechazo. De ahí que tampoco exista objeción alguna para que la solicitud de concurso llegue en un momento posterior.

b) En segundo lugar, el deudor, conocedor ya de la petición, puede permanecer totalmente inactivo. Ello implicará la no utilización de cualquiera de los diversos mecanismos que el legislador le otorga.

La consecuencia, entonces, será asimismo la estimación de la pretensión sin procedimiento contradictorio alguno. Repárese que el deudor es reconocido como parte sin necesidad de comparecer en forma (art. 184.1 PLC). Y repárese también que tales efectos legalmente se unen a un único y concreto comportamiento omisivo, la falta de oposición, que, sin embargo, resultaría compatible con actuaciones defensivas positivas como el planteamiento de declinatoria o la interposición de recurso.

c) A dicha pasividad, y nos referimos a la total, se contrapone como tercera -o quizá mejor segunda (lo es ante la solicitud)- opción del deudor emplazado el seguimiento de una conducta activa. Conducta activa que puede revestir formas de muy variada naturaleza y distinta trascendencia.

En efecto, aunque todas ellas tienen en común "un hacer" del presunto insolvente, conviene diferenciar:

$1^{\circ}$ ) Por un lado, la conformidad con el concurso instado, el allanamiento, que supone un acto de disposición con resultados vinculantes, si concurren ciertos requisitos, para el juzgador en orden a su estimación (art. 17.1 PLC).

No existe incompatibilidad, salvo la que se deriva del sentido común, con la utilización simultánea de vías de resistencia procesal, declinatoria o recurso de apelación. Ahora bien, en el supuesto excepcional de que el deudor adoptara tal proceder, que se justificaría fundamentalmente por razones de competencia, la ley proyectada no prevé, aunque seguramente debería, que el tribunal espere a dictar el auto de declaración de concurso a que se haya resuelto uno u/y otro (arts. 11 y 14 PLC).

$\left.2^{\circ}\right)$ Por otra parte, la disconformidad, discrepancia o resistencia frente a la solicitud que, lejos de arbitrarse en un único acto procesal, se reconduce a tres distintos dependiendo del tipo de defensa que se quiera utilizar: por falta de presupuestos procesales -declinatoria o recurso de apelación-, por ausencia de condiciones materiales -oposición-.

-La declinatoria se regula en el artículo 11 del PLC. Es el medio que se otorga al deudor para poner de manifiesto los defectos de jurisdicción y competencia (fundamentalmente se piensa en la internacional y territorial, art. 9 PLC) que puedan concurrir en el tribunal que conoce del concurso. Pero además:

-Es proceder compatible con la utilización de cualquier otro instrumento defensivo, tanto procesal -apelación-, como sustantivo -oposición-, y, por supuesto, con 
comportamientos pasivos; incluso, podría pensarse, con el allanamiento en el intento de atribuir competencia a juez distinto.

-Y se ordena cómo técnica carente de efectos suspensivos, lo que permitirá la continuación de los actos que comportan el resto de vías elegidas. Únicamente se paralizará la decisión del procedimiento contradictorio abierto con la formulación de oposición (art. 11.2 PLC). No obstante, en el hipotético caso de una conducta del deudor consistente en plantear declinatoria por falta absoluta de jurisdicción o de competencia genérica u objetiva, pero no formular oposición, incluso allanarse, el inmediato auto de declaración de concurso que se anuda a tales actitudes debería, en nuestra opinión, esperar hasta la resolución sobre el defecto jurisdiccional o competencial alegado. Lo contrario no dejaría de ser, al menos, antieconómico (el art. 238 LOPJ, que entiendo prevalente, dispone la nulidad), y, desde luego, no creo que la falta de resistencia material por la conformidad con la solicitud implique, en sí misma considerada, una renuncia a la pretensión interpuesta con la declinatoria. La reforma proyectada, sin embargo, no establece excepciones.

-El recurso de apelación que procede frente a la providencia de admisión a trámite de la solicitud de concurso se ordena en el artículo 12 del PLC. Del mismo interesa destacar:

-Que se trata de un instrumento puesto disposición del deudor para combatir aquella resolución judicial y obtener su revocación.

-Que se basa fundamentalmente en la falta de presupuestos o requisitos procesales, distintos de jurisdicción y competencia, y, por ello, debe predicarse su compatibilidad con la declinatoria y la formulación de oposición. Tampoco existiría inconveniente alguno en que el deudor antes de ser emplazado instara su propio concurso y tras dicho acto recurriera con el objeto de que finalmente la situación concursal declarada se calificara de voluntaria (art. 21 PLC).

-Que se admite, por expresa disposición legal, en un solo efecto, lo que en ciertos casos puede plantear una compleja problemática: declaración de concurso previa, bien por falta de resistencia bien incluso tras la audiencia del deudor si se opuso, y decisión ulterior del recurso revocando la resolución de tramitación impugnada. Los perjuicios para el tan renombrado principio de economía procesal son evidentes. La técnica utilizada es, pues, sumamente defectuosa.

-Por último y como figura central y ordinaria en la práctica forense, se sitúa la oposición a la solicitud, mecanismo mediante el cual el deudor, resistiéndose materialmente -aquí se encuentra la diferencia fundamental de contenido con los anteriores figuras-, intenta conseguir una resolución de fondo desestimatoria del concurso instado (art. 17.2 PLC). Para llegar a la misma se prevé un procedimiento contradictorio. $\mathrm{Y}$ es que la oposición, frente al allanamiento, no se encuadra en la categoría de actos de causación que determinan el pronunciamiento del juez, sino entre los de obtención o postulación que exigen además, antes de la resolución y sea cual sea su sentido, la facilitación de una previa discusión (art. 18 PLC).

Así las cosas, resulta difícil trasladar el esquema que viene realizándose sobre las posturas a adoptar por el demandando frente a la demanda. La diversidad de actitudes que puede asumir el deudor, su compatibilidad y las consecuencias que a ellas se 
anudan hacen que la alternativa no se sitúe exactamente entre personarse o no y, personado, en contestar o no y, contestando, en allanarse u oponerse. Las opciones legales van más allá $\mathrm{y}$, si dejáramos a un lado la declinatoria y el recurso de apelación y nos centramos en las aquí reguladas, parece que las mismas caminan en dos diferentes direcciones. En primer término, declaración de concurso sin más trámites: solicitud del propio deudor, allanamiento y no oposición. En segundo lugar, decisión al respecto tras un debate preliminar, la oposición sería el acto iniciador y la comparecencia el posterior. Diversidad que mantendremos nosotros también y que da lugar a los dos siguientes apartados.

\section{ALLANAMIENTO, OMISIÓN DE ACTIVIDAD Y PETICIÓN ULTERIOR COMO CAUSAS DE LA DECLARACIÓN INMEDIATA DE CONCURSO.}

Son tres las actitudes del deudor que originan una resolución judicial estimatoria de la pretensión concursal sin anterior procedimiento contradictorio. Son, como vimos, posturas diversas, de naturaleza distinta que se equiparan en torno a los efectos que producen pero que, fuera de ello, no es posible homologar.

La solicitud del propio concurso no es en sí misma considerada conducta frente a la petición formulada por el acreedor o cualquier otro legitimado. Contrariamente, la no oposición o el allanamiento sí son posturas "versus" la solicitud, aunque la primera, puramente pasiva, implica un no hacer y la segunda conlleva un determinado comportamiento activo.

\section{La posibilidad de conformarse.}

Partiendo de la admisión a trámite de la solicitud de concurso instado por el acreedor o por cualquier otro legitimado, el deudor emplazado puede allanarse a la pretensión del peticionario (art. 17.1 PLC).

Enfrentado, en principio, a la oposición -aunque mucho menos frecuente en la práctica forense-, es el allanamiento un acto procesal de parte, demandada evidentemente, mediante el cual muestra su conformidad con la pretensión interpuesta $\mathrm{y}$, consiguientemente, con el otorgamiento de la tutela judicial -declaración de concurso- pedida. A dicha conformidad, nada lo impediría, podría acompañarse la propuesta anticipada de convenio o la solicitud de liquidación de la masa activa (arts 103-105 y 141 PLC). Y, en cualquier caso, la misma, origina la finalización del procedimiento por decisión de fondo favorable.

Siendo como es conceptuación unánimemente aceptada por doctrina y

jurisprudencia y reconociendo como se reconoce -expresamente además- la viabilidad de esta figura en el Proyecto de Ley Concursal, resta tan sólo precisar sus elementos configuradores, tres como ahora veremos, y concretar forma y momentos de realización.

Antes de continuar, sin embargo, conviene recordar que el allanamiento ha resultado ser en la praxis judicial conducta inhabitual o, si se quiere, sumamente excepcional. En el proceso de declaración civil, y las razones son obvias, las partes, en este caso el demandado, se han venido inclinando mayoritariamente por su terminación 
mediante acuerdo, que lógicamente se prefiere a cualquier manifestación unilateral del poder de disposición que se les otorga (arts. 19-22 LEC). Del mismo modo podría concluirse en el procedimiento concursal, téngase en cuenta que la transacción figura en la enumeración legal de las situaciones que ponen fin al concurso (art. 176.1.5 ${ }^{\circ}$ PLC).

\subsection{Aspectos básicos del allanamiento.}

Su consideración como acto procesal del instado, la conformidad que encierra y los efectos que a su atención se anudan constituyen los principales elementos identificadores del allanamiento.

\subsubsection{Acto procesal del deudor. Requisitos subjetivos.}

Se trata de un acto procesal del deudor. Ni tiene naturaleza material ni procede, tampoco podría, del solicitante o de ambas partes conjuntamente.

Ello significa su imposible confusión con instituciones jurídico sustantivas. Y también su necesaria distinción con otras figuras procesales, unilaterales o no, que asimismo conducen al fin del proceso mediante el ejercicio de poderes dispositivos: por un lado, la renuncia que tiene como causante al actor peticionario del concurso, por otro, el convenio transaccional caracterizado por su bilateralidad.

Desde esta perspectiva debe advertirse que si bien el allanamiento para ser válido y eficaz no requiere asentimiento alguno de la parte contraria, sí exige la concurrencia en la persona del deudor de determinadas aptitudes y condiciones:

-Capacidad para ser parte y procesal, en primer lugar. Recordar entonces: $1^{\circ}$ ) Que, si se actuara a través de representante voluntario, es preciso mandato expreso al respecto (art. 1713.II CC); $2^{\circ}$ ) Que, si lo hiciera mediante representante necesario, tratándose de personas jurídicas, también el órgano societario correspondiente habrá debido conferirle dicha facultad; $3^{\circ}$ ) Que, en el hipotético supuesto de representación legal, la autorización judicial parece, aunque no es opinión pacífica, exigible (arts. 166, 271.3을 1810 y 1811 CC, según nos refiramos a padres o tutores). El problema sería el tiempo para su consecución.

-Legitimación, en segundo lugar (art. 3 PLC).

-Y, por último, capacidad de postulación procesal, actuación mediante abogado y procurador (art. 184.2 PLC), este último con poder especial que le habilite para allanarse (art. 25.2.1 ${ }^{\circ}$ LEC).

\subsubsection{Conformidad con la pretensión. Requisitos objetivos}

El contenido de este acto procesal es la expresión de la conformidad del deudor con la declaración de concurso interpuesta. El allanamiento encierra, pues, una declaración de voluntad de aceptar la tutela judicial pedida referida, en este caso, a la proclamación de su situación concursal.

De acuerdo con ello puede afirmarse: 
a) Que estamos ante una manifestación más del principio dispositivo que informa también, aunque con algunas matizaciones, el procedimiento que examinamos. Manifestación, además, cuya concreción no precisa aducir causa alguna por resultar "irrelevante lo que pueda pensar o decir sobre los fundamentos de la pretensión" con la que se conforma (De la Oliva, DPC-II, pág. 434).

b) Que como poder de disposición que es presupone, por un lado, la disponibilidad de la materia sobre la que recae y, por otro, exige el respeto a ciertos límites.

Desde luego la previsión normativa de su posibilidad permite afirmar sin lugar a dudas el carácter disponible de la declaración de concurso. Y, aunque en principio el silencio del legislador concursal sobre la existencia de condicionantes para su válido ejercicio pudiera conducir a una negativa, lo dispuesto en el artículo 21.1 de la LEC, de aplicación supletoria, obliga a entender que el allanamiento:

-No podrá hacerse en fraude de ley.

-No podrá contrariar el interés general.

-No podrá perjudicar a terceros. En este sentido y antes de concluir sobre la inviabilidad o inatendibilidad de la disposición realizada ha de tenerse en cuenta que el concurso, por propia naturaleza, afecta, y puede además que desfavorablemente, a sujetos distintos, acreedores fundamentalmente, de las partes iniciales del procedimiento. Lógicamente una interpretación similar (tan amplia) carecería de sentido pues imposibilitaría prácticamente la realización de esta conducta que no deja de estar permitida por ley.

c) Que, en tanto en cuanto la conformidad recae sobre la pretensión interpuesta y ésta es única e indivisible, no cabe la posibilidad de allanamientos parciales.

d) Que instituciones procesales diversas son la admisión de hechos y la prueba de confesión -interrogatorio de parte- con reconocimiento de los desfavorables. No sólo pueden provenir de ambos litigantes, sino que no tienen como objeto la pretensión, no determinan la inmediata terminación del proceso y la resolución a dictar puede ser desestimatoria.

\subsubsection{Finalización anormal del procedimiento mediante resolución de fondo} favorable.

Los efectos del allanamiento son claros. El juez, inmediatamente, dictará auto declarando el concurso (sin que sea de aplicación el art. 395 LEC sobre costas, art. 20 PLC, y pudiendo, en su caso, pronunciarse sobre la propuesta anticipada de convenio o la liquidación, arts. 105.2 y 141.2 PLC).

No puede sorprender entonces que se incluya el allanamiento entre los modos anormales de terminación del proceso. Y no por disconformidad con las normas jurídicas ordenadas al efecto (De la Oliva, DPC-II, pág. 426), sino por evitar, al suprimirse los trámites anteriores legalmente previstos, la contradicción necesaria y previa para lograr el convencimiento del juzgador en orden a emitir el correspondiente juicio. 
Y tampoco origina perplejidad su clasificación como acto de causación. El allanamiento exige del órgano jurisdiccional no sólo una resolución al respecto, sino que su pronunciamiento lo sea en un determinado sentido, siempre favorable a la pretensión del solicitante. Incongruente será la decisión que no respete tal vinculación.

Únicamente podrá apartarse tribunal en dos supuestos:

a) Si aprecia el incumplimiento de los requisitos subjetivos que han de concurrir en la persona del deudor: capacidad para ser parte, procesal, legitimación o de postulación.

b) Si estima vulnerados los límites objetivos legalmente establecidos: el allanamiento va en contra del interés público, perjudica a terceros o se realiza en fraude de ley.

En ambas hipótesis el control puede producirse "ex officio". Y, o bien se pone fin al proceso por falta de presupuestos procesales, en el primer caso cuando fueran insubsanables o resultaron insubsanados, o bien, rechazando la conformidad prestada por apartarse de sus condicionantes legales, se ordena que la tramitación siga su curso. Parece lógico entonces que al deudor se otorgue un nuevo plazo para oponerse, que sería, lógicamente, de cinco días.

\subsection{Forma y tiempo de realización.}

a) Que el allanamiento tiene que ser expreso es cuestión afirmada desde siempre y desde luego no controvertida. La voluntad de conformarse con la pretensión procesal que encierra este acto no puede deducirse de conductas diversas, expresas o tácitas, surgidas de la persona frente a la que se dirige la solicitud.

Otra cosa es, ciertamente, que las consecuencias examinadas, declaración inmediata de concurso, se anuden a ciertos comportamientos del deudor, fundamentalmente omisivos, como la incomparecencia o el silencio. Obsérvese que aquí estaríamos ante el incumplimiento de una carga procesal que no exigiría verificación de requisito alguno, y no ante el ejercicio de un poder de disposición condicionado por el respeto a ciertas exigencias objetivas.

Partiendo, pues, de ese carácter expreso no existe previsión alguna sobre su plasmación oral o escrita. Parece lógico pensar que ambas formulaciones -que en todo caso y claramente deben recoger la aceptación de la tutela pretendida, luego no la simple admisión de hechos- sean viables y que lo sean en función del trámite en el que el allanamiento vaya a producirse. De este modo y situándose en el momento previsto por el artículo 17 del PLC vuelve a parecer lógico entender que se efectúe por escrito en acto "ad hoc" o incluso con planteamiento subsidiario de oposición; ni la preparación del recurso de apelación ni la declinatoria serían continente adecuado para reflejar dicha conformidad.

b) Que el allanamiento puede efectuarse en cualquier tiempo del procedimiento es también aseveración común, aunque no exenta de problemas.

En realidad el legislador concursal únicamente se refiere a la posibilidad de allanarse en el plazo establecido para la formulación de la oposición. Sin embargo, el 
artículo 19.3 de la LEC admite la realización de los actos de disposición en cualquier momento de la primera instancia, de los recursos o de la ejecución de sentencia. La única limitación deriva de su propia naturaleza.

Así las cosas:

$1^{\circ}$ ) Un allanamiento anterior al emplazamiento es imposible. Y las razones son obvias: no puede conformarse con algo que se desconoce, al menos oficialmente.

$2^{\circ}$ ) Un allanamiento posterior en esta primera fase procedimental, aunque sea sumamente improbable, no debe entenderse inadmisible. Desde el traslado de la solicitud y hasta la finalización del plazo impropio otorgado para dictar la resolución sobre el concurso podría el deudor allanarse. Y si lo hiciera en la comparecencia ninguna objeción existiría a su formulación oral, consignada en el acta correspondiente (art. 146.2 LEC).

$3^{\circ}$ ) Un allanamiento en fase de recursos, dictada pues resolución contradictoria sobre la solicitud del deudor pero todavía no firme, no siempre sería viable. No lo sería cuando la pretensión impugnatoria tuviere por objeto la revocación del acto declarando concurso. En caso contrario, y en nuestra opinión, la posibilidad de allanarse en apelación no debería negarse.

Es la propia naturaleza de este acto procesal puesta en relación con el sentido del fallo recurrido la que conlleva similar respuesta. Repárese:

-Que, si la solicitud fue estimada y apeló el deudor (en tanto en cuanto legitimado y posiblemente único agraviado), sus poderes de disposición unilateral se dirigen al recurso mismo. Podría, pues, desistir con el resultado, al situarnos en esta fase del proceso, de adquisición de firmeza de la decisión de declaración de concurso impugnada.

-Que, si la solicitud fue rechazada recurriendo el acreedor peticionario, el deudor seguiría disponiendo de aquella facultad de aceptación de la tutela inicialmente pedida. Dicha tutela vuelve a ser pretendida en apelación al suplicarse la revocación del auto impugnado y una nueva decisión sobre el fondo favorable, lógicamente, a los intereses del solicitante.

\section{Falta de oposición}

Sobre el deudor, que tiene la condición de parte haya o no comparecido en forma (art. 184.1 PLC), recae la carga procesal de oponerse a la solicitud de concurso. Ahora bien, siendo como es un imperativo interés propio puede perfectamente permanecer inactivo.

A esta omisión de actividad -a la que debe asimilarse una formulación de oposición defectuosa- el legislador ha anudado una consecuencia concreta, la declaración de concurso, coincidiendo así con los efectos producidos por el allanamiento.

\subsection{Alguna precisión sobre el supuesto de hecho normativo.}


Una primera lectura de la expresión legal, si el deudor no formulara oposición en plazo, conduce a entender que dos son las situaciones que pueden producir esa decisión inmediata del órgano jurisdiccional.

En primer término, la ausencia real de resistencia, sobre el fondo, se entiende. A dichos efectos será indiferente que haya comparecido o no el deudor, que haya realizado algún acto de defensa procesal o no. Lo único relevante desde esta perspectiva es la falta absoluta de oposición, la no presentación del escrito contestando y objetando materialmente los fundamentos de la solicitud. Tal omisión es la que origina la finalización anormal del procedimiento.

En segundo lugar, su planteamiento extemporáneo. Aquí realmente la reacción frente a la pretensión se produjo, el acto procesal de oposición se formalizó, pero se llevó ante los tribunales fuera de plazo, transcurridos los cinco días otorgados para ello y computados desde el siguiente a la comunicación de su emplazamiento. La improrrogabilidad de los plazos junto con las dificultades para una hipotética interrupción -por causa de fuerza mayor (art. 134 LEC)- hace que la declaración inmediata del concurso sea regla general y prácticamente única en este supuesto.

A una y otra situación debería unirse, pese al silencio normativo al respecto, una tercera, seguramente infrecuente en la práctica, pero no por ello imposible de suceder. Nada impide que la facultad de oponerse a la solicitud se ejercite defectuosamente más allá de sus condiciones estrictamente temporales. El incumplimiento de tales requisitos procesales, bien inicialmente, bien tras el ofrecimiento de corrección si fueran subsanables, ha de conllevar idéntico resultado. Lo contrario, la simple preclusión y continuación del procedimiento, no tendría sentido al menos en la filosofía de la ley proyectada. Consiguientemente la verificación de su ausencia conducirá también a una implícita inadmisión de este escrito y a la decisión favorable, pero no contradictoria, de la pretensión concursal.

\subsection{Sus consecuencias jurídicas: estimación de la solicitud.}

Desde luego las diferencias que en este punto se producen entre proceso de declaración civil y el concursal no necesitan mayor comentario.

En aquel: a) Si el demandado no se persona se le declara en rebeldía con los efectos de todos conocidos (arts. 496-508 LEC). b) Si comparece en forma pero no contesta la demanda, o lo hace defectuosamente, se excluye su posibilidad de realizar este acto procesal. c) $\mathrm{Y}$ en ambos casos seguirán su curso los trámites establecidos sin que puedan asimilarse tales conductas, salvo disposición legal en contrario (art. 441 LEC), ni al allanamiento ni a la admisión de hechos (art. 496.2 para la rebeldía), pero entendiendo, sin embargo, que virtualmente contienen una negativa a los hechos y fundamentos de derecho de la demanda y la petición de rechazo de la misma.

En el procedimiento concursal que examinamos, por contra: a) La inactividad total del deudor no conduce, ni podría (tal situación ha sido ignorada por el legislador concursal y entiendo que con conocimiento de causa, por lo que la aplicación de la Ley de Enjuiciamiento Civil en este punto sería inviable), a que se dicte resolución judicial por la que se le tenga como rebelde. b) La falta de oposición o su inadmisión tampoco supone la simple preclusión de esta posibilidad de contestar (art. 136 LEC). c) Y una y otra postura, equiparadas legalmente, no permiten la continuación del procedimiento 
sino comportan su finalización anormal mediante la estimación judicial de la pretensión. Dan lugar a los efectos del allanamiento que acabamos de examinar y no originan una resistencia implícita ni tampoco una admisión de hechos.

El tribunal, por tanto, debe, constatado el transcurso del plazo sin presentar en forma oposición, haya realizado o no alguna otra actividad, dictar auto declarando el concurso. Y sería decisión automática que no exige verificación de requisito alguno, ni procesal -cuyo control se habría realizado con la admisión a trámite-, ni material excluyendo así la necesidad de probar los hechos constitutivos del objeto del proceso (art. 6.2 en relación con el 17 PLC)-. No obstante, la gravedad de esta consecuencia requiere una mayor diligencia si cabe en el traslado de la solicitud y emplazamiento. El derecho fundamental a la tutela judicial efectiva se vería claramente lesionado si no se realizará dicho acto de comunicación y llamamiento al proceso con totales garantías de conocimiento. Repárese que no se prevé un segundo emplazamiento.

\section{Instancia del propio concurso y auto declarándolo.}

El deudor puede, y debe por disposición legal, solicitar la declaración de concurso (arts. 4 y 5 PLC). Partiendo de ello no sorprendería que en la práctica se configure como primer -y posiblemente único también- peticionario. Es él quien está en mejores condiciones para conocer la insolvencia, actual o inminente, que le afecta (art. 5.1 PLC) y quién puede verse sancionado si no formula pretensión al respecto (arts. 163 y 164 PLC).

No obstante, nada impide que cualquier otro legitimado -acreedores incluidos- la presente simultáneamente ante el mismo o distinto juzgado (art. 9.1 PLC) y sea admitida a trámite en primer lugar. Y tampoco existe inconveniente alguno en que aquellos se adelanten en la promoción del procedimiento concursal -también se derivan ventajas (o evitan inconvenientes) de una diligencia similar (art. 90.5 PLC)- y, por consiguiente, que la del deudor llegue en un momento posterior.

Esta situación es la recogida en el artículo 17 del PLC, aunque el legislador limita temporalmente el supuesto fáctico de la norma en cuestión a la instancia de propio concurso previa al emplazamiento. Tres consideraciones entonces:

a) "Dies ad quem", en principio, será el inmediatamente anterior a la fecha de comunicación del emplazamiento. La referencia final no puede situarse en la emisión de la correspondiente resolución pues no es presumible su conocimiento.

b) Una solicitud del deudor efectuada en dicho ínterin resulta imposible de encuadrar entre las posturas a seguir frente a la petición contra él dirigida, la desconocería. Precisamente por ello y por otras razones evidentes nunca podrá asimilarse a la figura de la reconvención. Recuérdese que ésta supone el ejercicio de una nueva y distinta acción, con inversión de las posiciones procesales iniciales, a realizar junto a la contestación a la demanda (Diez-Picazo, DPC-II, pág. 268 y 269). Y precisamente por ello no existe inconveniente alguno en utilizar, una vez conocida, los 
medios defensivos procesales y materiales dispuestos por la futura ley (arts. 11, 12 y 17 PLC)

c) La posibilidad de solicitudes ulteriores a esa fecha, aunque discutible, no creemos deba negarse. Ciertamente no parece que aquí el legislador pensara en ellas. Quizá entendió que el deudor una vez conocida la pretensión, podía, con idénticos efectos, allanarse o no oponerse. Pero el artículo 13 del PLC no distingue y el problema es que, en estos casos, la declaración sería siempre de concurso necesario (art. 21 PLC) y la admisión a trámite podría haberse recurrido y resultar posteriormente revocada.

En otro orden de cosas, dictar, inmediatamente, auto declarando el concurso de acreedores es la consecuencia legalmente prevista y no sin razón. Se prescinde de la tramitación contradictoria que se establece para resolver las pretensiones del acreedor, $\mathrm{u}$ otro legitimado, precisamente por el reconocimiento del estado de insolvencia que se anuda a la propia instancia. Resulta entonces innecesario probar la concurrencia del presupuesto objetivo (y parece que la del resto de requisitos también) y con ello la apertura de un debate previo a la resolución. Ahora bien, debe advertirse que la lógica de esta opción legal quiebra si tenemos en cuenta que el deudor también puede oponerse por falta de los requisitos del concurso (subjetivo, objetivo -por su diferente configuración en función del solicitante- y legitimación). En estos casos, no importaría la declaración del concurso en sí, sino su calificación de necesario a voluntario.

Desde una perspectiva puramente organizativa no se olvide que la solicitud del deudor se incorporará a los autos incluyéndose en la sección primera cuyo encabezamiento, sin embargo, seguirá correspondiendo a la inicialmente formulada y admitida a trámite (art. 15 PLC).

\section{OPOSICIÓN A LA SOLICITUD Y TRAMITACIÓN CONTRADICTORIA}

\section{En general.}

Legalmente configurada como alternativa al allanamiento, la oposición del deudor no sólo representa la opción ordinaria o común a seguir por el sujeto pasivo del procedimiento concursal, sino también y además la construcción del mismo bajo el criterio "audita parte debitoris".

En efecto, a diferencia de la tramitación dispuesta para la solicitud del deudor, donde se prevé su decisión inmediata, la ordenada con ocasión de petición del acreedor $\mathrm{u}$ otro legitimado exige, para ser eficazmente resuelta, un debate contradictorio previo. Debate que precisamente se introduce a través de la formulación de resistencia, contenido fundamental del acto procesal de oposición que examinamos, y que continúa con la celebración de comparecencia. Con ello, pues, se da cumplimiento a disposiciones constitucionales relativas a la prohibición de indefensión facilitando o posibilitando la vigencia de principios básicos del proceso. El de audiencia sería el que más importa en este momento. Recuérdese su esencialidad desde la perspectiva de las partes, pero también su consideración como instrumento técnico eficaz para la actividad jurisdiccional (dispositivo psicológico apropiado para garantizar la aplicación exacta de la ley y la imparcialidad del juzgador, Montero, DJ- I, pág. 322). 
En cualquier caso y con las salvedades examinadas en el apartado anterior, la tramitación contradictoria deviene obligatoria. Bajo ningún concepto puede posponerse: ni por petición en tal sentido del solicitante -sobre la base, o sin ella, de razones de urgencia que comprometan el buen fin del concurso (art. 733 LEC)-, ni por la concurrencia de "determinados hechos de especial gravedad" (Ilustre Colegio de Abogados de Madrid, IALC-2001, pág. 49).

No hay, por tanto, norma general y excepciones. La regla es única, resolución "audita parte". Y lo es por decisión expresa del legislador quien fue advertido del doble riesgo: a) para la masa, si el deudor aprovecha este lapsus temporal realizando operaciones que vayan en perjuicio de aquella o constituyendo pruebas documentales con idéntica finalidad, y b) para el propio deudor, en el supuesto de que fuera solvente, por la incertidumbre que produce de modo necesario esta tramitación y la publicidad que conlleva lo que puede comprometer la viabilidad de la empresa hasta entonces con posibilidades objetivas de recuperación. Y, sobre todo y lo que es más importante, fue informado de su solución: "no sólo la drástica reducción de los plazos establecidos para la tramitación de la solicitud de concurso necesario", sino también la modificación del sistema excepcionando de este incidente previo cuando "el acreedor al formular la solicitud alegue y acredite situaciones prácticas especialmente graves" (Ilustre Colegio de Abogados de Madrid, IALC-2001, pág. 48 y 49).

Consiguientemente lo dispuesto en los artículos 14, 17 y 18 del PLC permite afirmar sin ninguna duda que tal planteamiento no ha sido asumido ni querido por el titular de la potestad legislativa. Quizá no adivinó peligro en la segunda situación, quizá en la primera lo entendió salvaguardado por la previsión de medidas cautelares (art. 16 PLC), pero lo cierto es que la oposición, configurada como carga procesal para sujeto pasivo, introduce la contradicción sin que existan excepciones a la misma más que las derivadas de la propia conducta del deudor.

Por ello es por lo que este acto procesal:

a) Nunca podrá asimilarse a los mecanismos legalmente establecidos para posibilitar la contradicción una vez dictada resolución "inaudita parte". La ausencia de un pronunciamiento de tal naturaleza impide su confusión con los medios impugnación destinados a cumplir una función similar y también, aunque su idéntica denominación pueda desconcertar, con actividades específicas que posibilitan la posterior defensa del sujeto pasivo (en medidas cautelares, por ej., arts. 739-742 LEC).

b) Sí podrá equipararse, con alguna matización, a la primera y principal actividad del demandado frente a la demanda: la contestación. Con ella comparte no sólo su normalidad -ambas constituyen estrategia ordinaria como lo prueba una práctica forense mayoritaria en tal sentido-, sino también, y por lo que aquí y ahora interesa destacar, su procedencia, objeto y naturaleza.

$\left.1^{\circ}\right)$ Respecto a la primera cuestión, estamos ante un acto de la parte demandada, del sujeto frente al que se dirige la solicitud. En este caso el deudor (arts. 14 y 17 PLC).

La posibilidad de que puedan oponerse personas distintas, aún cuando tengan interés directo y legítimo en el resultado del procedimiento, debe negarse (en contra CGPJ, IALC-2001, pág. 28 y 29). Ciertamente la normativa procesal civil permitiría su intervención, pero -y dejando un lado que temporalmente sería muy difícil: ni se 
suspende el curso del proceso ni se retrotraen actuaciones (art. 13.2 y 3 LEC)- tal conclusión no sería admisible con el Proyecto de Ley Concursal. En todo momento sujeto del emplazamiento y de la oposición es el deudor (arts. 14 y 17 PLC). A quien acredite interés legítimo se le faculta para recurrir el auto de declaración de concurso (art. 19.3 PLC), y, aunque legalmente se advierte que pueden haber comparecido con anterioridad, esta expresión no legitima que lo hagan oponiéndose a la solicitud (obsérvese que tampoco se les concede dicha posibilidad cuando el instante fue el propio deudor). Su intervención -que, salvo en ciertos supuestos (Banco de España Comisión Nacional del Mercado de Valores...), plantea el problema previo del conocimiento- se podrá producir en el trámite de vista y siempre que no se hubiere celebrado todavía, bien para negar la procedencia del concurso, bien para apoyarla, sobre todo si hubieran sido posteriores solicitantes y para evitar los efectos anudados a un desistimiento, incomparecencia o simplemente mala defensa del primero (art. 14.2 PLC).

$\left.2^{\circ}\right)$ En relación con su objeto, el mismo es la resistencia a la pretensión formulada por el actor o solicitante. Resistencia que aquí, como veremos en el apartado siguiente, se produce únicamente desde una perspectiva material.

$3^{\circ}$ ) Finalmente uno y otro acto se configuran como carga procesal. Sobre el deudor recae el imperativo en interés propio de comparecer y formular oposición. Su inobservancia da lugar (y en este punto las consecuencias difieren) a que se dicte resolución inmediata, sin más trámites, de declaración de concurso.

\section{Los motivos para oponerse. Delimitación negativa y positiva.}

Que, con carácter general (a salvo de intenciones relativas a la calificación del concurso como voluntario), el deudor pedirá en su oposición resolución desestimatoria de la solicitud, auto no declarando el concurso, es algo evidente que no exige mayor explicación. Sí la requiere, sin embargo, la determinación de las causas justificativas de dicha petición.

A ellas se refiere el artículo 17.2 del PLC. Pero su tenor literal lejos de resolver la cuestión, la oscurece. En una primera interpretación, mantenida por el CGPJ en su informe al Anteproyecto de Ley Concursal (2001), la única resistencia posible deriva de la ausencia del presupuesto objetivo del concurso (pág. 28). Una segunda, más correcta en nuestra opinión, permitiría al deudor oponerse por causas diversas, en principio, sin limitación. Se apoyaría en el carácter potestativo de la expresión utilizada que no sólo debe entenderse en el sentido de inexistencia de obligación de defenderse.

Semejante amplitud, sin embargo, resulta inviable desde una perspectiva sistemática y a la luz de otros preceptos del Proyecto de Ley Concursal. De acuerdo con él puede señalarse:

a) Que, negativamente, la oposición no es trámite apropiado para denunciar la falta de presupuestos procesales. Los defectos de jurisdicción o competencia sólo pueden alegarse en forma planteando declinatoria (art. 11 PLC); el resto, incluida la 
inobservancia de los requisitos exigidos a la solicitud, deberán ponerse de manifiesto a través del recurso de apelación procedente frente a la providencia de admisión a trámite (art. 12 PLC).

b) Que, positivamente, la oposición es acto procesal encaminado a atacar el fundamento de la pretensión. En él se contendrán las defensas materiales o de fondo, sin excepción. De este modo podrá afirmarse tanto la ausencia del presupuesto objetivo (la insolvencia no existe, existe pero no conforme con los hechos externos legalmente establecidos o es inminente pero no actual), como, mucho más difícilmente, la del subjetivo (quizá los supuestos más problemáticos se planteen en relación con la herencia y ciertas entidades de derecho público), e incluso la del relativo a la legitimación pues no todos los acreedores son legítimos a estos efectos e incluso pueden no gozar de tal condición (art. 3 PLC). Si la declaración de concurso cuya desestimación se pretende exige la concurrencia de todos y cada uno de ellos, lógico será que el sujeto pasivo del procedimiento pueda defenderse sobre la base de objetar la presencia de cualquiera.

Partiendo de lo anterior y siempre sin olvidar la preclusión que se anuda a este trámite, la articulación de la resistencia material que comporta podrá realizarse:

$\left.1^{\circ}\right)$ Mediante una negación de los hechos que sirvieron de fundamento a la petición del acreedor, u otro legitimado, o, si se quiere, a través de la afirmación de su inexistencia. Tales hechos, es cierto, principalmente vendrán referidos a la insolvencia (art. 2.4 y 17.2 PLC), pero nada excluye, todo lo contrario, que versen sobre los demás presupuestos.

Una negativa similar debería, huyendo de fórmulas genéricas, individualizarse con expresión, en su caso, del porqué correspondiente (Diez-Picazo, DPC-II, pág. 260). Téngase en cuenta que la misma convierte en controvertidos las alegaciones fácticas realizadas y, por tanto, necesitadas de prueba (a cargo del solicitante si quiere que su pretensión sea estimada), y que el tribunal podrá considerar el silencio o las respuestas evasivas del deudor como admisión tácita de los hechos que le sean perjudiciales (art. 405.2 "in fine" LEC).

$2^{\circ}$ ) Mediante una admisión de la fundamentación fáctica de la pretensión y una negación de las consecuencias jurídicas que se anudan a ella.

El ejemplo más claro lo proporciona el propio legislador cuando permite al deudor que base su oposición en que, aun existiendo los hechos constitutivos del presupuesto objetivo, realmente no se encuentra en estado de insolvencia. Aquellos hechos dejan de ser controvertidos, no necesitarán ser probados, pero, por el contrario, sí deberá acreditarse, y sobre el deudor recaerá la carga de hacerlo, su solvencia. Prueba que será necesaria para el rechazo de la solicitud y que habrá de basarse en la legalmente establecida para llevar contabilidad si estuviera obligado a ello.

$\left.3^{\circ}\right)$ Mediante la alegación de hechos nuevos de naturaleza sustantiva, aunque de diferente condición, cuya apreciación conduce a la desestimación de la pretensión en tanto en cuanto contrarrestan los constitutivos de la misma. Se trataría del planteamiento de excepciones, evidentemente materiales, basadas en supuestos fácticos impeditivos, extintivos o excluyentes. Que sea infrecuente su utilización en el procedimiento 
concursal no implica considerarlas defensas imposibles. En absoluto. Podrán alegarse tales hechos y debidamente probados conducirán asimismo a una resolución denegatoria del concurso instado.

\section{El acto de oposición, su examen por el tribunal y la citación a comparecencia.}

La resistencia del deudor a la solicitud en cualquiera de las modalidades que acabamos de examinar ha de formularse en plazo (art. 17.1 PLC) y, lógicamente, en forma.

Temporalmente dispone el deudor de 5 días para su presentación. Cinco días que se computarán desde el siguiente a la comunicación, válidamente practicada, del traslado de la solicitud y del emplazamiento correspondiente.

Formalmente es posible entender, pese al silencio del legislador al respecto, que el sujeto pasivo se opondrá mediante escrito debidamente articulado, fechado y firmado (art. 184.2 PLC). Otra conclusión es difícil de mantener máxime cuando las contestaciones verbales, cuando así son previstas, se realizan en la vista o comparecencia de los correspondientes juicios y aquí la oposición es previa a la citación para el trámite oral.

Como es lógico, a este escrito deberán acompañarse los documentos procesales poder notarial de representación procesal, por ej.- y materiales correspondientes, aunque, dado el tenor literal del artículo 19 del Proyecto, estos últimos no se verán afectados por una regla de preclusión. Preclusión que tampoco incidirá en la proposición de pruebas al ser posible su planteamiento tanto en este acto como en la propia audiencia.

Formulada oposición, el juez, al día siguiente, citará a las partes a una comparecencia (art. 17.2.II PLC). Previamente, sin embargo, habrá debido examinarla al objeto de verificar el cumplimiento de los requisitos -subjetivos, objetivos, formales y temporales- controlables de oficio por el órgano jurisdiccional y, en su caso, de posibilitar la corrección de aquellos defectos subsanables en que hubiere incurrido (falta de firmas...). Su inobservancia, inicial o posterior, originará, como vimos, la declaración inmediata de concurso.

Concurriendo los mismos es cuando el tribunal, acordando implícitamente la admisión de la oposición y ordenando su traslado al solicitante, efectuará la correspondiente citación a las partes con determinación del lugar, fecha y hora para que comparezcan y actúen.

Dos consideraciones al respecto parece conveniente realizar.

En primer término, la necesidad de hacer constar en dicho acto de comunicación ciertas prevenciones: a) La advertencia de que se personen con todos los medios de prueba que puedan practicarse en la vista y entiendo además que sería útil informar sobre la posibilidad de citación judicial de las personas que, por no poder presentarlas las propias partes, han de declarar en la comparecencia (art. 429.5 LEC); b) La 
indicación, dirigida al deudor, para que lo haga además con los libros de contabilidad de llevanza obligatoria (lógicamente si estuviera obligado a ello); y c) El aviso, aunque el apoyo normativo es cuestionable, de las consecuencias de su respectiva ausencia (arts. 17.2.II y 18.2 y 3 PLC), incluyéndose la posibilidad de considerar admitidos los hechos del interrogatorio conforme a lo dispuesto en el artículo 304 de la LEC si no comparecieron personalmente pese a haber sido citados judicialmente (art. 440.1.II LEC).

En segundo lugar, la posible extensión de las personas citadas más allá del acreedor instante y del opositor. De este modo y por un lado se debería citar a los solicitantes posteriores cuyas peticiones se unieron a los autos (art. 14.2 PLC), pero también, y por otro, a los sujetos que, por datos obrantes en el propio procedimiento, puedan verse afectados por la resolución que en su momento se dicte e incluso cuando el tribunal advirtiera indicios de utilización del proceso con fines fraudulentos (art. 150.2 LEC). Banco de España, Comisión Nacional del Mercado de Valores, o Fondo de Garantía Salarial, cuando del proceso pudiera derivarse su responsabilidad para el abono de salarios o indemnizaciones de los trabajadores (art. 184.1 PLC), se situarían entre ellos. 